ISSN: $1130-3743$

\title{
LA IMAGEN SOCIAL DEL PROFESORADO EN LA PRENSA
}

\author{
The social image of the teacher in the press
}

\section{L'image sociale de l'enseignant dans la presse}

\author{
Amparo Consuelo CIvila Salas \\ Universidad de Málaga. Facultad de Ciencias de la Educación. Departamento de \\ Teoría e Historia de la Educación. Campus de Teatinos, s/n. 29010 Málaga. \\ Correo-e: acs@uma.es
}

Fecha de recepción: enero de 2005

Fecha de aceptación definitiva: abril de 2005

BIBLID [(1130-3743) 17, 2005, 227-254]

\section{RESUMEN}

Este artículo presenta un trabajo de investigación que ha consistido en el análisis de la imagen social del profesorado que se transmite en la prensa diaria. La imagen que se transmite desemboca en una visión negativa de la imagen social del hecho educativo en general, y afecta negativamente al proceso de aprendizaje que experimentan los alumnos, al proceso de enseñanza que desarrollan los profesores e incluso a la salud psíquica y física de éstos. Tan importante puede resultar el desprestigio gratuito, generalizado y desmesurado del profesor que merece ser tomado más en serio por estudios enfocados hacia la búsqueda de soluciones. Los medios de comunicación social pueden modificar la dirección de esta circunstancia si comienzan a transmitir una imagen del profesor más sincera, realista y ajustada, salvando los estereotipos.

Palabras clave: identidad, teoría de la educación, formación del profesorado, realización profesional, imagen social y medios de comunicación. 


\section{SUMMARY}

This article presents a work of research that has consisted of the analysis of the social image of the teaching professorship that is transmitted in the daily press. The image that is transmitted ends in a negative vision of the social image of the educational fact in general, and concerns negatively the learning process that the pupils experience, to the process of education that the teachers develop and even to the psychic and physical health of these. So importantly it can turn out to be the free, widespread and enormous loss of prestige of the teacher who deserves to be taken more seriously by studies focused towards the search of solutions. The media of social communication can modify the direction of this circumstance if they begin to transmit a more sincere, realistic and exact image of the teacher, saving the stereotypes.

Key words: identity, educational theory, teacher's training, professional achievement, social image, social means.

\section{SOMMAIRE}

Cet article présente un travail de recherche qui a consisté en l'analyse de l'image sociale du professorat qui est transmise dans la presse quotidienne. L'image qui est transmise aboutit à une vision négative de l'image sociale du fait éducatif en général et concerne négativement le processus d'étude que l'expérience d'élèves, au processus d'éducation que les enseignants développent et même à la santé psychique et physique d'entre ceux-ci. Si d'un air important il peut s'avérer être la perte gratuite, répandue et énorme de prestige de l'enseignant qui mérite d'être pris plus sérieusement par des études concentrées vers la recherche de solutions. Les médias de communication sociale peuvent modifier la direction de cette circonstance s'ils commencent à transmettre une image plus sincère, réaliste et exacte de l'enseignant, sauvant les stéréotypes.

Mots clef: identité, théorie de l'education, formation des enseignants, épanouissement professionnelle, image social, moyens de communication. 


\section{APUNTES TEÓRICOS SOBRE LA IMAGEN SOCIAL DE LA FUNCIÓN DOCENTE}

\subsection{Contexto del deterioro}

En los años setenta se comienza a contraponer a la imagen idílica del profesorado $^{1}$, como ser modélico en sus virtudes y buenos hábitos ${ }^{2}$, una visión conflictiva de la enseñanza y de los propios profesores que se transmite a la sociedad. Los medios de comunicación de masas fueron los principales transmisores de dicha imagen, pues ellos empezaron a divulgar las imperfecciones y lagunas del sistema educativo, mientras culpaban de ellas a los propios profesores. Tras el franquismo, comenzaba una época en la que ya se podían criticar abiertamente las deficiencias de los servicios públicos sin pasar censura. Años antes, todas eran buenas noticias, y las únicas "malas" eran aquellas que al Régimen le interesaba que fueran ampliamente conocidas por todo el pueblo español, por lo general para afianzar en los ciudadanos $^{3}$ el sentimiento de rechazo y condena hacia ciertas ideologías.

Así pues, vemos cómo la imagen social del profesorado se desprestigia desde que los medios de comunicación de masas, y la comunidad en general, empiezan a convertir en problemas educativos todos aquellos conflictos sociales y políticos que van surgiendo, sin que los responsables de la política educativa hayan intervenido a su favor, salvo contadas ocasiones ${ }^{4}$. No obstante, con el paso de los años los responsables de la educación se han dado cuenta que no es buena opción que el profesorado cargue con la culpa de errores y lagunas socioeducativas, puesto que de esta forma el sistema educativo también pierde respeto y confianza. En estas condiciones: "Los profesores en nuestra sociedad contemporánea se enfrentan a unas circunstancias cambiantes que les obligan a hacer mal su trabajo, enfrentándose además a una crítica generalizada, que, sin analizar esas circunstancias, considera a los profesores como los responsables inmediatos de los fallos del sistema de enseñanza" (Esteve, 1997, 20-21). En ocasiones los profesores se sienten desvalidos, abandonados a su suerte y a los ataques indiscriminados del resto de la comunidad.

1. Durante el artículo voy a emplear la palabra "profesor/ado" como generalidad de docentes y maestros, excepto en las citas literales. No empleo "educador" puesto que desde el nacimiento de un perfil profesional específico para la Educación Social, se reserva para sus trabajadores. También he desestimado usar la palabra "enseñante", porque parece ignorar la tarea básicamente formativa de esta profesión.

2. Para conocer más a fondo las características del profesor ideal, véase Voli, F. (1996) La autoestima del profesor. Manual de reflexión y acción educativa. Madrid, PPC, 34 y ss.

3. A lo largo de todo el artículo, para referirme a un grupo de personas, emplearé la generalidad, simplemente para evitar la pesadez textual de indicar el masculino y el femenino de dicha palabra cada vez que la emplee.

4. Valgan como ejemplo las campañas publicitarias que ha desarrollado la Consejería de Educación de la Junta de Andalucía, con el fin de enaltecer la labor de los profesores. 
Por otro lado, desde que la escuela ha dejado de coincidir con las demás instituciones que participan en la socialización del niño o del joven en los valores y en los patrones que deben ser transmitidos y que dan lugar a una socialización convergente, el profesor ha perdido seguridad en su trabajo. Un profesional inseguro sólo consigue el deterioro de su actividad. Los profesores han pasado en poco tiempo de ser admirados por su impecable labor a ser compadecidos por la situación tan compleja en la que desarrollan su trabajo. Ya no poseen el monopolio de los conocimientos. En este contexto, los profesores han dejado de ser «agentes monopolizadores" para convertirse en "agentes mediadores" entre los alumnos y la masa de información que reciben constantemente (García García, 1986).

Desde otro punto de vista, se pueden distinguir cuatro aspectos del enfrentamiento del profesor con la postmodernidad. En primer lugar, se produce la ampliación del rol del profesor. En segundo lugar, éstos sufren una sensación de sobrecarga de responsabilidades. En tercer lugar, las metas educativas tradicionales empiezan a derrumbarse. Y, en cuarto lugar, los métodos y estrategias que utilizan están sometidos a una crítica constante (Hargreaves, 1996).

Sumado a todo este conflicto, el profesor se encuentra con el grave problema de tener que luchar por no perder la consideración de "profesión". Dentro del campo de estudio de la sociología, se defiende la tesis de que existen unas profesiones mayores y unas menores. Las profesiones mayores son aquellas que solucionan problemas concretos -como la medicina, la abogacía, las empresas...-, las cuales suelen fundamentar su actividad en un conocimiento científico y/o tecnológico. En cambio, las profesiones menores poseen fines más ambiguos, una ordenación menos rigurosa y su ejercicio no calma la ansiedad humana; precisamente entre estas últimas se encuentra la enseñanza. Las profesiones menores, en cuanto dejan de tener un significado social, pierden la categoría de "profesión" para pasar a ser "arte". Se puede afirmar que la docencia es una profesión que lucha por mantener esta categoría porque "al ser considerado profesional, uno entra, por así decir, dentro de una élite, tanto en lo económico como en lo social, con todas sus implicaciones en forma de poder, brillo y fama" (Wanjiru, 1995, 186).

En el mismo sentido, la docencia es una ocupación que se encuentra a medio camino entre la profesionalización y la proletarización, a estas ocupaciones en términos sociológicos se les denomina "semiprofesiones"; pero existe un factor muy importante que interviene a favor de la profesionalización de la actividad educativa: "[...] es la naturaleza específica del trabajo docente, que no se presta fácilmente a la estandarización, a la fragmentación extrema de las tareas, ni a la sustitución de la actividad humana por la de las máquinas" (Fernández Enguita, 1990, 160).

Una condición que puede haber influido notablemente en el deterioro de la imagen del profesor ha sido la burocratización de su trabajo, cuya consecuencia directa es la de someter al profesor a un continuo proceso de supervisión, evaluación y control. A este respecto, podemos distinguir cinco tipos de control. Un primer tipo de control sería el "político", referido a los profesores que desempeñan cargos en su centro. Un segundo tipo sería el control "legal", que permite a los 
ciudadanos exigir ante un juez que se cumplan sus derechos educativos. El tercer tipo de control es el del "mercado", según el cual padres y alumnos eligen la escuela más apropiada y, en algunas ocasiones, hasta profesor. El cuarto es el control «burocráticon, mediante el cual la Administración educativa vigila el cumplimiento de las reglamentaciones y las modifica cuando lo considera necesario. $\mathrm{Y}$, en último lugar, no por ello menos importante, está el control "profesional", referido a la continua revisión de los compañeros en la toma de decisiones en el aula (Marcelo, 1994).

A pesar de tanto control, causado - como ya hemos comentado- por la burocratización de la docencia, el profesor realiza aislado su trabajo. Vivimos en la cultura del individualismo en la que cada profesional realiza sus actividades en solitario, sin más contacto con los compañeros que el estrictamente necesario para el desarrollo de las tareas "obligatorias" de coordinación.

El contexto organizativo hace que los profesores trabajen aislados unos de otros, no se favorece o incentiva la aportación del conocimiento, reclama el mantenimiento del orden y el control de la conducta de los alumnos más que otra cosa, exige adherencia a directrices burocráticas, colegiadamente no se enfatiza la experimentación, la propia estructura física de los centros no es muy favorable, etc. (Gimeno, 1993, 89).

\subsection{La formación del profesorado}

Los programas de formación del profesorado desempeñan un papel fundamental en la actualización de las metodologías empleadas en educación, para que ésta no sea un proceso de enseñanza-aprendizaje desfasado con respecto al resto de la comunidad; porque las estrategias que antes funcionaban con la minoría de jóvenes que estudiaban, posteriormente no han resultado útiles al enfrentarlas a la universalización de la enseñanza (Esteve, 2003). El fracaso en los programas de formación del profesorado ha sido precisamente el fundamentarse sobre el modelo que establece una separación abismal entre la teoría y la práctica.

Si se concibe el conocimiento profesional como un conjunto de hechos, principios, reglas y procedimientos que se aplican directamente a problemas instrumentales, "la práctica", lógicamente, debe considerarse como un proceso de entrenamiento técnico, para comprender cómo funcionan las reglas y técnicas en el mundo real del aula, y para desarrollar las competencias profesionales exigidas para su aplicación eficaz (Pérez Gómez, 1988, 141).

Afortunadamente, una gran mayoría de los profesores en ejercicio están a favor de innovar y funcionar con autonomía. Éstos, preocupados por hacer bien su trabajo, denuncian que en la formación inicial no se les ha entrenado en nuevos métodos y demandan algún curso de reciclaje y formación permanente para conocerlos. 
Los profesores tienden a ejercer su pedagogía y su creatividad para ajustar el proceso de enseñanza hacia un aprendizaje oportuno de sus alumnos.

Aunque parezca incongruente, la propia Administración educativa, a la vez que no ofrece la formación más adecuada, sí que reivindica para el profesor la función de transformador e innovador social. En este sentido se requiere adoptar un modelo reflexivo y artístico de formación de profesores que los prepare para trabajar en las situaciones divergentes de la práctica educativa, aceptando que no existe un conocimiento y una solución específica para cada problema. El profesor debe reflexionar en la acción para crear las estrategias adecuadas que le permitan afrontar y definir cada problema; por consiguiente, la práctica se convierte en la esencia y eje central de los programas de formación de profesores (Furlong, Hirst, Miles y Pocklington, 1988; Pérez Gómez, 1988; Imbérnón, 1994).

Así pues, uno de los principales causantes de esta crisis en la profesión docente son aquellas políticas educativas que, por una parte, no han sabido ofrecer al profesor la capacitación necesaria para poder actualizar sus métodos según lo vaya demandando la sociedad; y, por el contrario, permiten que el profesor tenga que enfrentarse con una realidad ficticia que se les plantea durante su formación. Este desengaño, también denominado "shock del futuro" (Tofler, 1972), produce un tremendo desconcierto, una baja consideración social y una pérdida de valoración y de autoridad.

Desde hace ya varios años, muchos especialistas han analizado cuáles deben ser los conocimientos del profesor, estableciendo cuatro ámbitos en los que enmarcar esos conocimientos: 1) conocimientos propios de la materia o materias a impartir, 2) conocimientos de la estructura, normativa, funciones, materiales y demás aspectos que incidan sobre la institución educativa, 3) resultados alcanzados por la investigación y 4) conocimientos de los criterios y conductas que guían la práctica didáctica (Shulman, 1987). Desde un punto de vista mucho más filosófico se afirma que

[...] toda profesión se apoya en tres ámbitos: técnico, artístico y moral. El ámbito técnico-artístico engloba el saber y el ser capaz de llevarlo a cabo y de transmitirlo, con las destrezas necesarias que esto exige. [...] Pero además es menester incluir el ámbito moral, que exige la responsabilidad personal de cada educador, y que supone sobre todo un deber de actuar de tal manera que por encima de cualquier otra valoración se lleve a cabo aquello que beneficia a los alumnos y a la comunidad, y se deje de lado todo aquello que les puede perjudicar (Wanjiru, 1995, 40).

Además, no debemos olvidar que, desde los setenta, el profesor empieza a competir, como transmisor de conocimientos, con los medios de comunicación de masas -en especial con la televisión-, sin tener apenas recursos para tratarlos y sin conocer métodos que acerquen más sus clases a esa manera de informar. Parece una rivalidad entre profesores y medios de comunicación, cuando en realidad la incorporación de éstos al ámbito educativo no hace sino ampliar los contenidos a tratar en el currículum (González García, 1986). De nuevo nos encontramos con otro sentimiento de incompetencia y abandono hacia el profesor. En general, 
[...] el cambio acelerado del contexto social ha influido fuertemente sobre el papel a desempeñar por el profesor en el proceso de enseñanza, sin que muchos profesores hayan sabido adaptarse a estos cambios, ni las administraciones educativas hayan diseñado ninguna estrategia de adaptación, sobre todo en los programas de formación de profesorado, que no se han aplicado sistemáticamente para responder a las exigencias planteadas por dichos cambios (Esteve, Franco y Vera, 1995, 24).

Más aún, debemos considerar el resultado de las investigaciones de $\mathrm{E}$. Breuse (1984), el cual subraya el hecho de que el tiempo de formación empleado en temas de psicopedagogía y didáctica es inversamente proporcional a la edad de los alumnos con los que vaya a trabajar el profesor; mientras que las horas dedicadas al estudio de otras disciplinas es directamente proporcional. Además, señala que los profesores no están preparados para construir sus propios programas, ni para seguir la evolución que se produce en cuanto a metodologías y a técnicas.

También, según la investigación dirigida por M. de Miguel Díaz (1996), con respecto a la formación inicial recibida, los profesores reclaman una formación más adecuada a los aspectos prácticos de la enseñanza, lo que equivale a decir una formación más apropiada sobre esas habilidades didácticas que les permiten desenvolverse en el aula. En general, los profesores consideran al período de prácticas como el elemento de su formación inicial que más influencia tiene en su desarrollo profesional y condenan el exceso de contenidos científicos porque siempre pueden ser adquiridos posteriormente de forma autodidacta o a través de un sistema informal de enseñanza.

Una forma de remediar las deficiencias que los profesores van descubriendo en la práctica consiste en la formación continua, la cual debe potenciar su especialización como profesionales, debe mejorar su capacidad global y debe acercar las instituciones de formación del profesorado a los centros de enseñanza (Goble, 1980). La formación permanente del profesorado debe fundamentarse en tres líneas de actuación: 1. Reflexión, comprensión, interpretación e intervención sobre la propia práctica. 2. Actualización y confrontación, mediante el intercambio de experiencias. 3. Fomentar el trabajo colaborativo y los procesos de comunicación (Imbernón, 1994).

La formación del profesorado debe concentrar sus esfuerzos más en los significados de las tareas que en la propia aplicación de dichas tareas. Además se puede añadir que la formación debe preparar para asumir novedades, para salvar las dificultades y para solventar conflictos (Merazzi, 1983; Vera, 1988; Cox y Heames, 2000); porque la naturaleza interactiva de la comunicación del profesor con los alumnos siempre comporta la posibilidad de que surjan elementos o situaciones inesperadas. Realizando cambios sustanciales en la formación inicial y permanente de los profesores se puede avanzar hacia la mejora de su trabajo, y por tanto de la consideración social de este gremio. 


\subsection{Las exigencias sociales}

A partir de los años setenta, la sociedad pierde parte de su naturaleza compacta en mentalidad y en hábitos, la democracia trae pluralismo y con ella falta de unanimidad respecto a muchos aspectos de la vida social y de los servicios públicos, incluyendo el propio sistema educativo. De esta manera los profesores se ven acosados por exigencias muy diversas, ambiguas e incluso, en algunos casos, contradictorias. Sin embargo este incremento acelerado de demandas hacia el profesor no viene acompañado de un aumento de medios y recursos para poder satisfacerlas (Esteve, 1987; Vera, 1988; Marcelo, 1994; Ortiz Oria, 1995; Pablos, 1997; Esteve, 2003). En general, se puede decir que "la democratización y el desarrollo han creado exigencias que exceden, cualitativa y cuantitativamente, la capacidad de los sistemas tradicionales" (Goble, 1980, 15).

Entre la diversidad de exigencias, destacamos aquellas que reclamaban los cambios en la unidad familiar: los padres dedican menos tiempo a sus hijos, el número de hijos por familia se ha reducido notablemente y la implicación del resto de los familiares también es inferior; estas circunstancias crean una serie de lagunas que se pretende que sean cubiertas por el profesor (Merazzi, 1983). Al no satisfacerse esas exigencias, aparecen críticas indiscriminadas hacia el profesorado, las cuales van contribuyendo al desprestigio de la profesión docente y, por supuesto, indirectamente son causa del aumento significativo del número de bajas e incluso de abandonos. El constante juicio social al que está sometido el profesor ha llegado a desilusionarle y, en ocasiones, a provocarle el serio problema del estrés (Cooper y Travers, 1997; Esteve, 2003).

Este aumento creciente de responsabilidades sobre los profesores, lejos de producir una mayor profesionalización, al exigir ampliar conocimientos y especialidades, ha conducido a una proletarización de sus actividades: "Un proletario es un trabajador que ha perdido el control sobre los medios, el objetivo y el proceso de su trabajo. La proletarización no puede entenderse como un salto o cambio drástico de condición, sino como un proceso prolongado, desigual y jalonado de conflictos abiertos y larvados" (Fernández Enguita, 1990, 156-157). Esta proletarización ha provocado escasez de autonomía para los profesores sobre su actividad, y les ha llevado hacia una hiperresponsabilidad sobre nuevas y variadas cuestiones; tal es el caso de la integración, las áreas transversales, las necesidades afectivas, el multiculturalismo, etc. (Gimeno, 1993; Esteve, Franco y Vera, 1995; Buxarrais, 1997).

Las nuevas exigencias que surgen hacia los profesores aumentan el listado de las capacidades que éstos requieren (Buxarrais, 1997), tales como saber crear un clima escolar adecuado, crear situaciones que planteen problemas y contradicciones a la estructura moral, escuchar, aconsejar y ayudar en la formación, construir un modelo teórico propio y adaptado a la situación educativa concreta y que admita modificaciones, animar y analizar el funcionamiento de los grupos, interrogarse sobre uno mismo dentro de su práctica docente, mostrar neutralidad pedagógica y poder ofrecer diferentes soluciones ante un problema, otorgándole el mismo 
énfasis en todas las alternativas, diseñar actividades tendentes al desarrollo de la confianza de los alumnos, dirigir discusiones morales, poseer un autoconcepto ajustado y positivo sin necesidad de implicarse afectivamente de forma constante y afrontar situaciones potencialmente conflictivas.

A tal extremo llegan a influir las exigencias de la comunidad hacia un determinado profesional que es ampliamente conocido y extendido el fenómeno de lo "socialmente deseable", que ha sido definido como la "[...] tendencia del individuo a describirse según rasgos y descripciones que le parecen general y comúnmente admitidas por la sociedad"(Abraham, 1987, 43). En el campo de la docencia, este fenómeno puede producir un falso éxito en aquellos profesores que piensan que serán considerados buenos profesionales si reúnen las cualidades que la sociedad valora de su actividad. Bajo esta circunstancia, podemos afirmar que muchos profesores no evalúan el proceso y el resultado de su propio trabajo, sino la apreciación y valoración del mismo que hace el resto de la comunidad, lo cual puede repercutir en la formación de profesionales conformistas carentes de objetivos sólidos y justificables. Precisamente por estas razones, opinamos que el profesor debe saber filtrar, de entre todo el conjunto de exigencias, aquellas que realmente sean demandas lógicas y posibles dentro del ámbito educativo, separando éstas de aquellas que, por el contrario, estén fuera de contexto o sean puras utopías. Hace más de veinte años que esta situación se denunciaba de la siguiente forma: "[...] algunas exigencias que parecen imponerse a la escuela por parte de la comunidad, pueden proceder realmente de sectores representativos de intereses específicos y egoístas que existen dentro de la comunidad" (Goble, 1980, 78). Aquí se destacan las preferencias de los empresarios encaminadas hacia una escuela que entrene, seleccione e incluso discrimine en función de la capacidad productiva de los alumnos. Observamos también una mención a los responsables del orden que reclaman la pervivencia y transmisión de valores y principios tradicionales, para salvaguardar la autoridad de los adultos. Frente a estas exigencias altamente conservadoras en sus pretensiones, aparecen voces reformistas que aseguran alzar sus peticiones en representación del pueblo. Los docentes tienen que mantener el equilibrio entre las necesidades del individuo y las de la futura sociedad. En esos momentos aparece el gran conflicto de la tarea educativa: la educación prevé, pretende preparar al alumno para desenvolverse en una sociedad que aún no existe (Faure, 1974). En definitiva, "el profesor es un intermediario entre el mundo "real" y el mundo "ideal" " (Hoyle, 1969, 74).

\subsection{Perspectiva actual de la imagen del profesor}

En los últimos años, las expectativas puestas sobre la actuación del profesor han variado sustancial y formalmente. En general, la sociedad ya no piensa que la educación pueda igualar las diferencias entre los individuos, eliminando las clases 
marginales ${ }^{5}$, ni tampoco cree que la educación garantice un futuro profesional porque ya no asegura un puesto de trabajo acorde al nivel de estudios. En el aspecto en el que sí se ha dado un gran paso, es que actualmente la sociedad está empezando a dejar de creer que los profesores sean los culpables de todos los males sociales. Así, por ejemplo, se confía la búsqueda de más y mejores puestos de trabajo a la labor de las políticas sociales en pro del empleo, a los cursos de formación ocupacional para desempleados y a los de formación continua para personal en activo; además se muestra más preocupación por las reformas de la legislación laboral vigente. En otras palabras, la sociedad presente parece conocer que la buena preparación de los jóvenes ya no es una garantía de éxito sin el apoyo de una política sociolaboral adecuada. En este sentido, la actualización de los currículos asegura el ajuste de los estudios a las necesidades del mercado, o por lo menos así lo intenta; es decir, el que todos los ciudadanos en edad activa tengan su lugar en el mercado laboral es, en líneas generales, tarea de los equipos políticos de gobierno.

Sin embargo, hemos retrocedido en la consideración profesional del profesor ${ }^{6}$. Al descargarlos de la culpa de una serie de males sociales, no de todos, pierden responsabilidades y con ellas pierden relevancia en las jerarquías socioprofesionales. En los últimos años, están apareciendo nuevas ocupaciones e instituciones destinadas a dar solución a esos problemas sociales que sobrepasan la tarea educativa del profesor, así es el caso de los educadores y asistentes sociales, las plataformas de voluntariado, los centros de ocio educativo, las campañas informativas del Sistema de Atención Sanitaria -SAS-, los centros de acogida para inmigrantes, las instancias del Proyecto Hombre, los programas desarrollados por la Fundación de Ayuda contra la Drogadicción -FAD- ....y un largo etcétera de casos similares en los que prima la ayuda para solucionar y para evitar determinados males de la sociedad contemporánea. Así pues, con esa pérdida de responsabilidades, los profesores han dejado de gozar de una excelente consideración social, entendiendo que ‘...] la consideración social puede definirse como un conjunto de derechos y deberes que caracteriza la función de un individuo en sus relaciones con los demás» (Mollo, 1980, 60). En realidad, vivimos una situación realmente contradictoria, pues la sociedad reconoce que el profesor realiza un trabajo de capital importancia, a la vez que les asigna una posición social baja.

5. Es indudable que la escuela cumple una función reproductora, pues el fracaso escolar se concentra entre los alumnos de las clases inferiores o marginales. Esta función tiende a ser disuelta por la misma evolución social que ya no da tratamiento especial a los individuos que poseen un título o certificado de estudios

6. Es interesante analizar las opiniones de los profesores respecto a las ideas que pueden ser causa de una falta de reconocimiento profesional; para ello véase Fernández SánCHEZ, M. ${ }^{3}$ M.; NAVARRO, C.; Higuera, C. y Martínez Castro, E. (1993) Encuesta al profesorado de primaria y secundaria de la enseñanza pública: opiniones y actitudes ante sus condiciones de trabajo. Madrid, MEC, 64 y ss., 174-175. 
Probablemente el hecho de que los ciudadanos vuelvan a dar ese voto de confianza y respetuosidad arrancado anteriormente al profesorado está precisamente en manos de los medios de comunicación. Si volvemos a suministrar a los profesores la consideración social que merecen por su labor, seguramente mejorará su posición social, su estatus profesional, e incluso su propio autoconcepto (Ortiz Oria, 1995). Es necesario, aceptar que

[...] la consecución de un alto estatus para un grupo profesional no es sólo, ni fundamentalmente, una cuestión de voluntad ni de estrategias trabajadas por ese grupo, sino que en última instancia es otorgado por la sociedad en virtud de las condiciones sociales y los valores culturales en alza en un momento dado. En otras palabras, no es un objetivo fácilmente manipulable, sino que depende de complejos factores socioculturales que se materializan, en último lugar, en la valoración comparativa que la sociedad hace de las distintas profesiones (Gil Villa, 1996, 33).

Los estereotipos que nos llegan a través de los medios de comunicación social, en el caso de la docencia, se resumen en dos: el "ideal" y el "conflictivo" (Esteve y Fracchia, 1984; Vera, 1988). El primero es el que hace referencia a la consideración histórica del profesor como amigo, guía, cuidador y modelo del alumno, en el que confía toda la sociedad, porque resalta todos los matices positivos de la docencia. El segundo subraya todos los inconvenientes o lagunas del proceso educativo como errores imputables, casi en exclusiva, al profesorado, resaltando sus características más conflictivas. Tan injusto como parece el segundo estereotipo, también lo es el primero, por cuanto pone al profesor frente a un ideal utópico de desarrollo profesional. En realidad los dos estereotipos conviven y pueden incluso desarrollarse sobre un mismo profesor en dos momentos diferentes de su vida profesional. Es importante hacer notar que muchos profesores se preocupan por la existencia de esos estereotipos que se transmiten a la sociedad, simplemente por el interés comercial de los medios de comunicación (Rodríguez Penin, 2002).

Es preciso concluir este apartado sobre la imagen actual del profesor señalando pautas para mejorar su condición social: en principio se aconseja reestructurar la carrera, el salario y la promoción (Hoyle, 1969), y también se propone trabajar el potencial humano de estos profesionales (Abraham, 1993). Sin duda la primera iniciativa, y también la que puede resultar más productiva hacia la búsqueda de calidad en la enseñanza, es el reconocimiento social de la labor de los profesores (Esteve, 2003). Por consiguiente, resulta importante tener en cuenta que: "Para que las personas puedan ser felices en su trabajo, hacen falta tres cosas: deben estar dotadas para él; no han de ejercerlo en exceso; y tienen que sentir que lo desempeñan con éxiton (Cox y Heames, 2000, 146). 


\section{Estudio de LA IMAGEN DEL PROFESOR EN LA PRENSA DIARIA}

\subsection{Introducción}

En esta investigación se analiza la imagen social del profesorado que se transmite en la prensa diaria. Partimos del hecho de que la impresión transmitida de la actividad docente a través de la prensa diaria desemboca en el empeoramiento de la imagen social de la educación en general; lo cual afecta negativamente al proceso de aprendizaje de los alumnos, al proceso de enseñanza que desarrollan los profesores e incluso puede afectar a la salud psíquica y física de éstos. Tan importante puede resultar el desprestigio gratuito, generalizado y desmesurado de la función docente que merece empezar a ser tomado más en serio por estudios enfocados hacia la búsqueda de soluciones.

Es evidente que los medios de comunicación social pueden modificar la tendencia actual si comienzan a transmitir un estereotipo del profesor más sincero en comparación con el que se está desarrollando en la actualidad. El objeto de estudio de este trabajo de investigación es precisamente el análisis de la imagen social de profesores que transmite la prensa, conociéndose de antemano que la prensa escrita es el medio de comunicación más asequible para la realización de investigaciones y estudios.

Existen varios trabajos de investigación que sirven como antecedentes a este estudio, ya que aplican el análisis de contenido para encontrar temáticas educativas en la prensa escrita, pero el estudio que más se acerca a nuestros objetivos es el dirigido por J. Cabero y F. Loscertales (1998) en la Universidad de Sevilla. Con nuestra investigación vamos a trasladarnos algunos años después, al curso 2001-2002, con discusión legislativa de fondo, en este caso no sólo de educación general, la Ley de Calidad de la Enseñanza (23/12/2002), sino también una ley de carácter universitario, la Ley Orgánica de Universidades (21/12/2001) y otra de formación profesional, la Ley Orgánica de Cualificaciones y de la Formación Profesional (20/6/2002).

\subsection{Desarrollo}

Para esta investigación se fueron recopilando los textos que hacían referencia a profesores y que aparecieron, a lo largo del curso 2001-2002, en cinco periódicos diferentes: ABC, El Mundo, El País, La Vanguardia y Sur. A medida que se realizaban las localizaciones y lecturas de los textos, se iban diferenciando los temas y formando con ellos categorías. Además de considerar las palabras clave y los temas, también trabajamos otras seis categorías en cada uno de los textos: mes de publicación, sección del periódico, presentación, situación, extensión y género periodístico.

En el análisis de contenido que se ha realizado se han manejado tres programas informáticos: AQUAD Cinco, SPSS 11.5 y Excel, que han posibilitado el cálculo 
de frecuencias observadas y esperadas, la elaboración de tablas cruzadas, la definición de estadísticos no paramétricos y la constatación de hipótesis.

La tarea inicial consistió en recabar información para cubrir una serie de objetivos generales:

- Identificar las temáticas referidas al profesorado en la prensa escrita.

- Cuantificar el empleo de diferentes sustantivos -palabras clave- para designar la figura del profesor.

- Reconocer los géneros periodísticos en los cuales suelen aparecer estos textos referidos a profesores.

- Evaluar la extensión que se suele dar a estos textos.

- Cuantificar el empleo de fotografías y gráficos como acompañantes a estos textos.

- Identificar los lugares del periódico en los cuales se suelen colocar estos textos y valorar si es frecuente su presencia en portada.

- Evaluar qué diferencias existen entre los periódicos trabajados con respecto el tratamiento de textos que hacen referencia a profesores.

\subsection{Resultados}

El volumen de textos encontrados (ver Tabla 1) y sobre los que se llevó a cabo el análisis, fue de 863.

TABLA 1

DATOS DE DIFUSIÓN Y TEXTOS SOBRE PROFESORES ENCONTRADOS POR PERIÓDICOS

\begin{tabular}{|l|l|l|l|l|l|}
\hline & ABC & $\begin{array}{c}\text { EL } \\
\text { MUNDO }\end{array}$ & $\begin{array}{c}\text { EL } \\
\text { PAÍS }\end{array}$ & $\begin{array}{c}\text { LA } \\
\text { VANGUARDIA }\end{array}$ & SUR \\
\hline Difusión de ejemplares & 279.050 & 312.366 & 433.617 & 198.337 & 39.508 \\
Textos sobre profesores & 155 & 196 & 256 & 86 & 170 \\
Porcentajes/encontrados & $17,96 \%$ & $22,71 \%$ & $29,66 \%$ & $9,96 \%$ & $19,69 \%$ \\
\hline
\end{tabular}

Observando estos datos podemos afirmar que el promedio de textos sobre profesores que hay en cada periódico es proporcional a su difusión; excepto en un caso, porque el periódico de menor tirada, el Sur, demuestra una elevada preocupación por las cuestiones relacionadas con los protagonistas de la enseñanza. Esta conclusión coincide con varias investigaciones anteriores (Pérez Serrano, 1984; Nieto, 1986; Bartolomé y Sevillano, 1989; Cabero y Loscertales, 1998). El País, que es el periódico de mayor número de ejemplares, también tiene el porcentaje más alto de este tipo de textos, mostrando así una justa ocupación en el tratamiento de la figura social del profesor. 
La época de publicación de los 863 textos encontrados se concentra de forma muy desigual en cada uno de los periódicos. Así en $A B C$ y en Sur el mes de mayor número de publicaciones relacionadas con la figura del profesor fue septiembre; lo cual parece lógico teniendo en cuenta que es el mes de inicio del curso escolar y, por consiguiente, las cuestiones educativas están de actualidad. En La Vanguardia, además del mes de septiembre, sobresale significativamente el mes de febrero, porque se sucedieron diversos acontecimientos relacionados con profesores en ese mes que elevaron la proporción con respecto a otros meses o periodos. Estos acontecimientos que captaron la atención de La Vanguardia en especial, fueron fundamentalmente: las movilizaciones contra la recién aprobada LOU, las primeras discusiones sociopolíticas sobre la LOCE y los problemas ideológicos de presión ejercidos sobre catedráticos del País Vasco. En El Mundo el mes de mayor publicación de textos sobre profesores fue abril; las razones parecen ser, en primer lugar a la cercanía del final de curso y, en segundo lugar, una serie de sucesos polémicos en los que se vieron implicados profesores, tales como es el caso de la matanza de profesores y alumnos en un instituto de la ciudad de Erfurt (Alemania) o el despido de un catedrático (Agapito Maestre) de la Universidad de Almería al parecer por cuestiones políticas. En El País fue noviembre el mes de mayor concentración de estas publicaciones, demostrando el interés de este medio por la política educativa, puesto que no sólo son referencias al inicio de curso, sino también cuestiones dedicadas a las discusiones políticas y movilizaciones en torno a la LOU ya que su aprobación iba a tener lugar de inmediato, al mes siguiente.

\section{GRÁFICO 1}

DISTRIBUCIÓN PORCENTUAL POR MESES

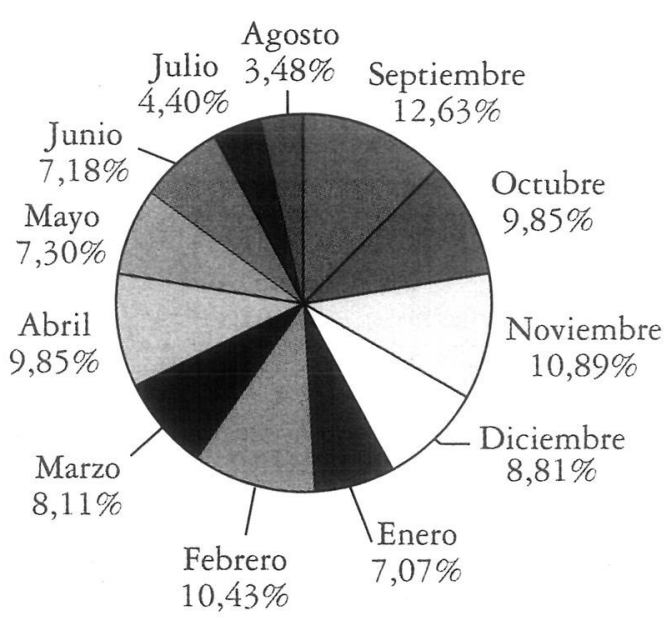

Teniendo en cuenta la suma de los textos encontrados en los cinco periódicos (ver Gráfico 1), los meses de septiembre ( $f=109$ ), noviembre ( $f=94$ ), febrero ( $\mathrm{f}=90)$, octubre $(\mathrm{f}=85)$ y abril $(\mathrm{f}=85)$ son los que más textos concentran, además en ese orden, aunque a decir verdad ninguno de ellos destaca significativamente por su alto porcentaje. Las razones de la concentración de textos en los 
meses de septiembre, noviembre, febrero y abril ya han sido comentadas. En el caso concreto del mes de octubre nos atrevemos a inferir que es debido al inicio de curso, en este caso para las enseñanzas superiores.

Por el contrario, se caracterizan los periodos vacacionales de Navidad ( $\mathrm{f}=10$, $1,17 \%)$ y de Semana Santa $(f=12,1,36 \%)$ porque en ellos son escasísimos los textos que se refierén a profesores; la causa parece ser el hecho de que sus actividades están institucionalmente paralizadas. Sin embargo, esta última afirmación no es corroborada por el hecho de que tampoco hay actividad educativa durante el periodo de las vacaciones de verano $(f=68,7,91 \%)$, pero en ellas se ha encontrado una cantidad apreciable de estos textos, centrados fundamentalmente en discusiones políticas en torno a la LOCE.

Con respecto a la sección del periódico en la que aparecen estos textos, es preciso subrayar que 263 aparecen en la sección "Sociedad", 199 en la sección "Regional" - "Andalucía"-, 183 en la sección específica para cuestiones de "Educación" y 114 en las secciones "Locales" -108 en la de "Málaga" del periódico Sur y 6 en la sección dedicada a "Barcelona" del periódico La Vanguardia-. En las otras secciones el número de textos encontrados no resulta significativo, por lo que apreciamos una alta concentración de este tipo de textos en tres secciones periodísticas: "Sociedad", "Andalucía" y "Educación" (ver Gráfico 2). Entre las otras secciones destacan los 35 y 33 textos encontrados en "Internacional" y en "Nacional" - "España»- respectivamente. En general, es relevante que destaque el número de textos localizados en la sección "Sociedad" y "Regional" «Andalucía", sobre los de la sección "Educación"; esto se traduce por un fuerte interés por informar sobre sucesos sociales y no sobre fenómenos específicos del ámbito de la enseñanza.

\section{GRÁFICO 2}

PORCENTAJE DE TEXTOS SOBRE PROFESORES POR SECCIONES PERIODÍSTICAS

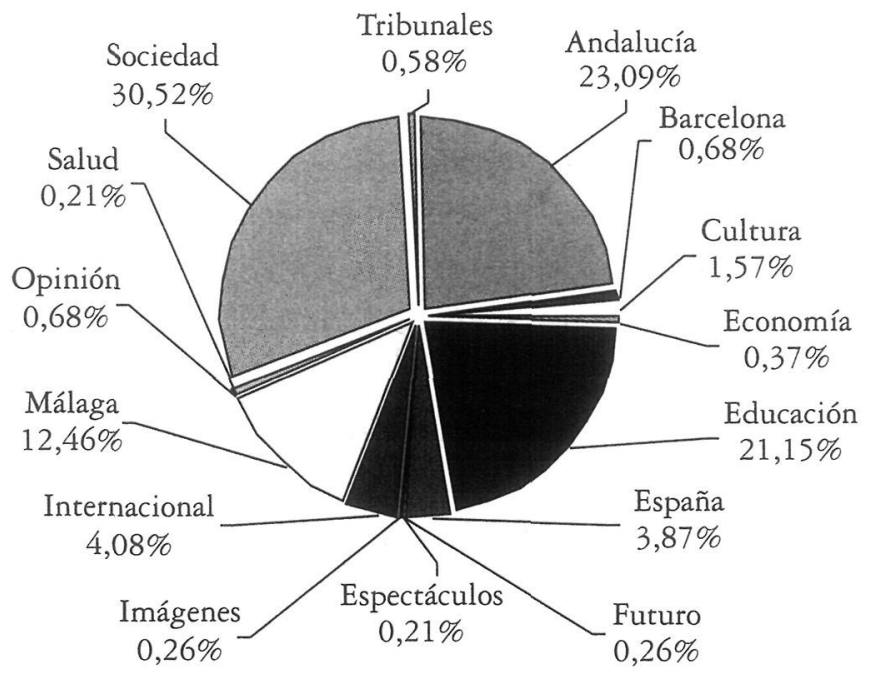


$\mathrm{Al}$ estudiar la forma en que se presentan los textos encontrados (ver Gráfico 3), debemos resaltar que en todos los casos se emplea el titular, excepto en dos -uno de El País y otro de La Vanguardia- que son textos que únicamente aparecen en portada y, por consiguiente, sólo llevan titular de portada. Es decir, sólo hemos encontrado dos textos cuya presentación completa se sitúa en portada, mientras que los otros titulares de portada corresponden a textos que luego continúan presentándose en el interior del periódico. De ahí que el total de titulares sea 861, y no coincida con el número total de textos recogidos. En general, los titulares de portada sólo se emplean en un $6,13 \%$ de los textos recogidos, lo cual nos transmite la escasa importancia que las empresas periodísticas conceden a los textos sobre educación.

\section{GRÁFICO 3}

PORCENTAJES DE PRESENTACIÓN

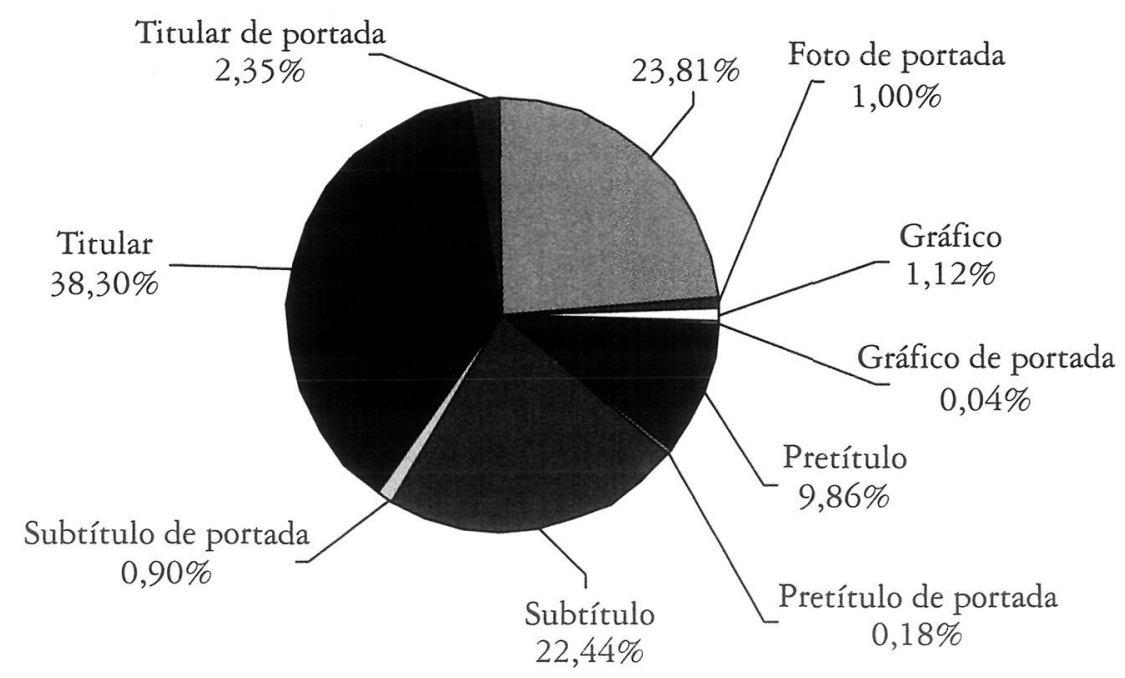

Se observa además que es bastante numerosa la aparición de subtítulos y de fotografías, 1.118 y 1.236 respectivamente. Sin embargo, el empleo de gráficos, antetítulos, fotografías y subtítulos en las portadas, es residual. Ha resultado demasiado bajo el acompañamiento de gráficos, sólo en un 8,17\% de los textos, cuando en realidad son temas que necesitan aclarar datos mediante la representación gráfica.

Teniendo en consideración que la localización de un documento en página impar o derecha es un privilegio porque en esa ubicación el lector le presta mayor atención (Vilches, 1987; Keene, 1995), debemos mencionar que los documentos sobre profesores se sitúan en el 58,03\% de los casos en página par ( $\mathrm{f}=501)$ frente al $41,97 \%$ de los que van en página impar ( $f=362$ ). Por consiguiente, encontramos cierta preferencia hacia la publicación de estos textos en página par, confirmando así la tendencia a no dar mucha importancia a los temas sobre profesores. 
Metiéndonos en el estudio de cada una de las posible situaciones (ver Gráfico 4), y coincidiendo con J. Cabero y F. Loscertales (1998), es preciso resaltar que pocas veces se reserva un sitio en la portada para referenciar temas relativos a profesores y/o alumnos; en nuestra investigación ese 7,01\% de presencia en portada se suele reservar para temas de huelga, discusiones de política educativa o graves sucesos sociales. La contraportada no suele emplearse para situar textos de esta índole, sólo hay 1 caso en El País y 17 en el Sur, por lo que no resulta un dato relevante. Esas apariciones en Contraportada en el periódico Sur se deben a la existencia en esa página de una sección dedicada exclusivamente a noticias sobre iniciativas sociales, entre las cuales se incluyen las educativas cuando son innovadoras y de alto interés social. Sin embargo, sí resulta significativo que el 46,61\% de todos los textos recogidos se coloque en páginas centrales y el 33,44\% en primeras páginas.

GRÁFICO 4

PORCENTAJES DE LA SITUACIÓN DE LOS TEXTOS DENTRO DEL PERIÓDICO

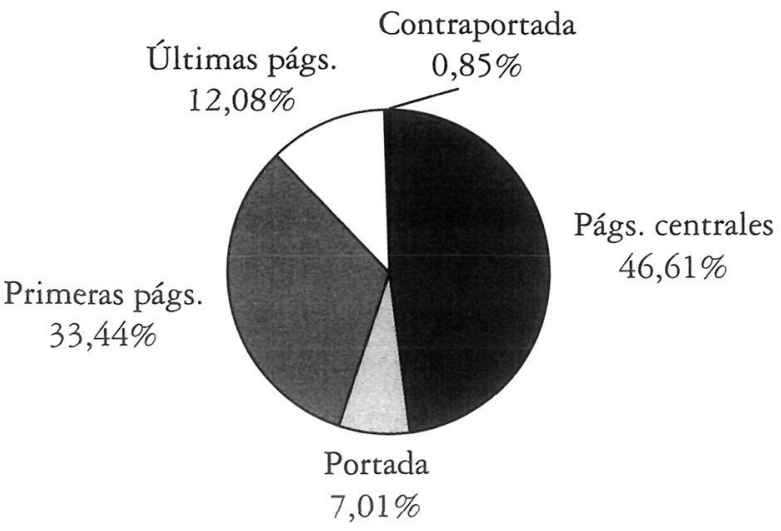

$\mathrm{Al}$ analizar los tamaños de estos textos encontramos que en los 155 recortes tomados de $A B C$ un $37,80 \%$ corresponde a una extensión grande y un $35,66 \%$ a una pequeña, siendo éstos los dos porcentajes más altos en su distribución. En el caso de El Mundo, El País y La Vanguardia, un 52,10\%, un 49,85\% y un $41,13 \%$ son los respectivos porcentajes de extensión pequeña, seguidos a distancia considerable, con un $22,72 \%$, un $21,43 \%$ y un $25,40 \%$ respectivamente, en la media página de ocupación. En el Sur también destaca la proporción de extensión pequeña con un $42,40 \%$, pero en este caso el segundo lugar se lo reparten la media página con un $19,95 \%$, la grande con un $18,37 \%$ y la muy pequeña con un $17,01 \%$. Merece ser destacado que sólo en el periódico $A B C$ se usa la página completa en una proporción relevante, siendo en este caso residual la extensión muy pequeña. Por el contrario, en los otros cuatro periódicos, la página completa es la extensión menos empleada, mientras que la presentación muy pequeña es bastante 
empleada con este tipo de textos. A partir de estos resultados del tamaño de los textos podemos inferir, coincidiendo con otros estudios (Pérez Serrano, 1984; Cabero y Loscertales, 1998), que en líneas generales la prensa no resalta el valor y el interés de las temáticas educativas porque éstas no resultan novedosas para los lectores.

Si nos fijamos en las extensiones del total de los textos recogidos (ver Gráfico 5), sin hacer distinciones entre periódicos, es preciso resaltar que la extensión pequeña alcanza el porcentaje mayor con respecto al resto, mientras que en el otro extremo encontramos el porcentaje residual de la extensión de página completa.

$\mathrm{Al}$ estudiar la frecuencia de los géneros periodísticos de estos textos, es necesario subrayar el alto número que representa la noticia en los cinco periódicos, seguido con bastante lejanía por el número de reportajes. El uso de Carta al director para textos sobre profesores sólo se presenta en 1 caso en el periódico $A B C$. También es preciso resaltar que no hemos encontrado ninguna de las palabras clave en los títulos, antetítulos y/o subtítulos de los siguientes géneros: editoriales, avisos y comunicados. Concluimos, pues, que la falta de participación de los usuarios a través de los géneros periodísticos a su alcance, se traduce por cierta apatía sobre el tema, hecho demostrado por los propios grupos editoriales al no querer expresar su particular opinión, que quizás pudiera comprometerlos en demasía.

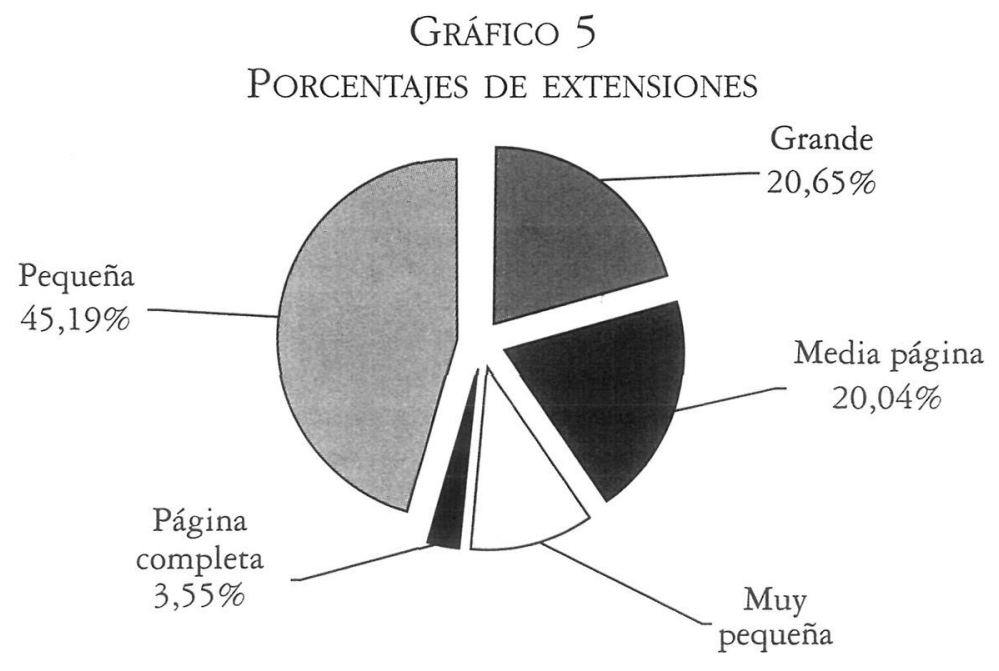

Coincidimos con otras investigaciones (Pérez Serrano, 1984; Nieto, 1986; Bartolomé y Sevillano, 1989; Cabero y Loscertales, 1998) en que el estilo periodístico más empleado para cuestiones educativas es la información. Según la clasificación de géneros tenida en cuenta en nuestro estudio, los géneros periodísticos más empleados han sido la noticia y el reportaje, porque en los temas que hacen referencia a la imagen del profesor se informa más que se opina.

Si nos fijamos en los porcentajes por géneros periodísticos empleados sobre el total de textos (ver Gráfico 6), observamos que el empleo del artículo de opinión, de la carta al director, del comentario y de la entrevista es casi residual. 
GRÁFICO 6

PORCENTAJES DE GÉNEROS PERIODÍSTICOS EMPLEADOS

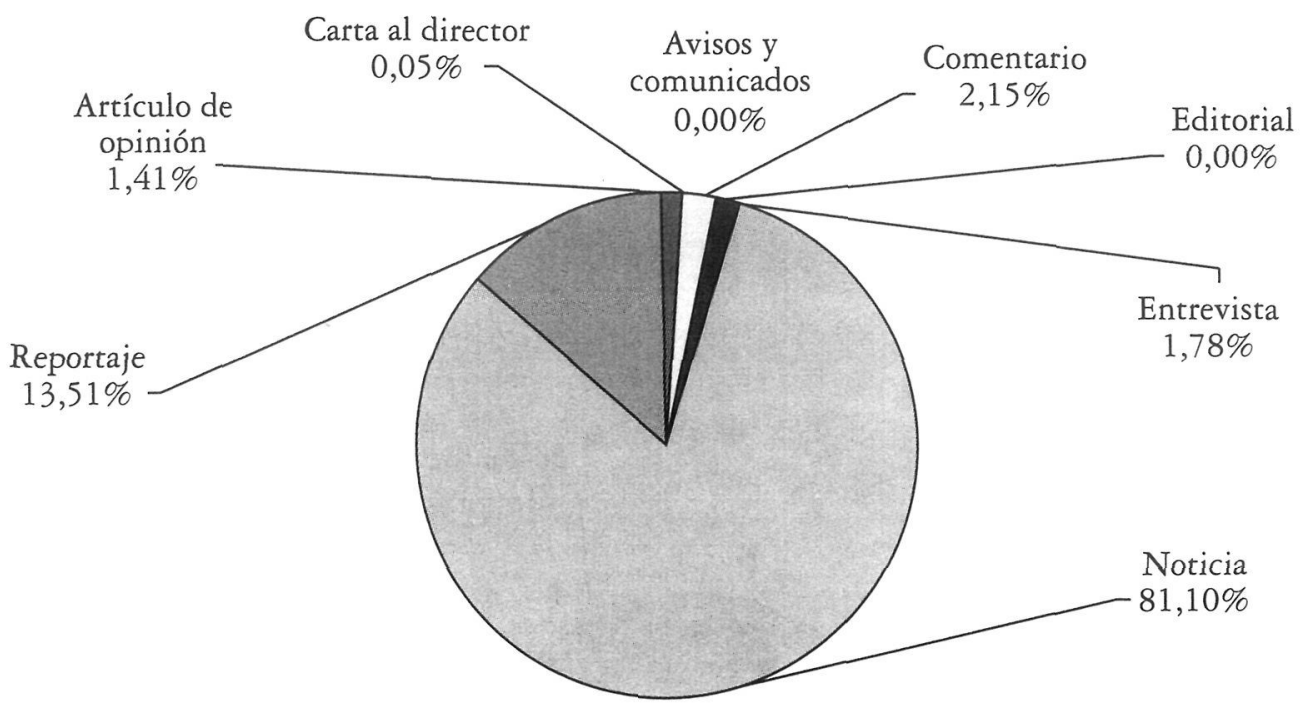

En lo referente a los temas que tratan estos textos (ver Gráfico 7), hay que decir que, considerando los porcentajes que superan el 10\% entre el total de los temas de profesores en cada periódico, en $A B C$ destacan los temas de Política (dopolítica) ${ }^{7}$, conflicto (do-conflicto) y despido (do-despido), en El Mundo y en El País sobresalen esos tres mismos temas además del tema Protesta (do-protesta). En La Vanguardia destacan los temas de disciplina (do-disciplina), maestría ${ }^{8}$ (do-maestría), política (do-política) y religión (do-religión). Mientras que en el Sur aparecen más repartidos los temas tratados, de forma que por encima de un 10\% se encuentran seis temas sin mucha diferencia numérica entre ellos -oscilan del 12,94\% al 11,18\%-; éstos son conflicto (do-conflicto), disciplina (do-disciplina), investigación (do-investigación), maestría (do-maestría), protesta (do-protesta) y religión (doreligión). De todo ello podemos deducir que sólo en el periódico Sur se tratan tanto aspectos sociales problemáticos que pueden vivir los profesores, como aspectos destacables dentro de su desarrollo profesional. En La Vanguardia también sucede algo similar al Sur, pero es preciso resaltar que el tema política tiene un porcentaje de 22,09\%, bastante más relevante que el de disciplina, maestría y religión, que no superan el 13,95\%. En los tres periódicos restantes está clara la dedicación casi exclusiva a los aspectos sociales problemáticos que viven los profesores, resaltando su actualidad y polémica. Coincidimos plenamente con los resultados obtenidos por J. Cabero y F. Loscertales (1998), porque en ese estudio, menton.

7. Los temas se han categorizado con el prefijo "do-" por no emplear completa la palabra "docu-

8. Entendiendo por maestría cuando se ejerce una profesión de forma ejemplar y excepcional. 
sobre los temas de profesores destacaron, por este orden, temas administrativos, temas científico-educativos y temas de política; en nuestro estudio al incluir en política los temas administrativos, sobresalen los primeros con mayor diferencia porcentual. También nos acercamos al resultado de la investigación de D. Bartolomé y M. ${ }^{a}$ L. Sevillano (1989), puesto que los temas que encuentran en común hacen referencia, en su mayoría, a cuestiones de política.

\section{GRÁFICO 7}

PORCENTAJE DE LOS TEMAS QUE HACEN REFERENCIA AL PROFESOR

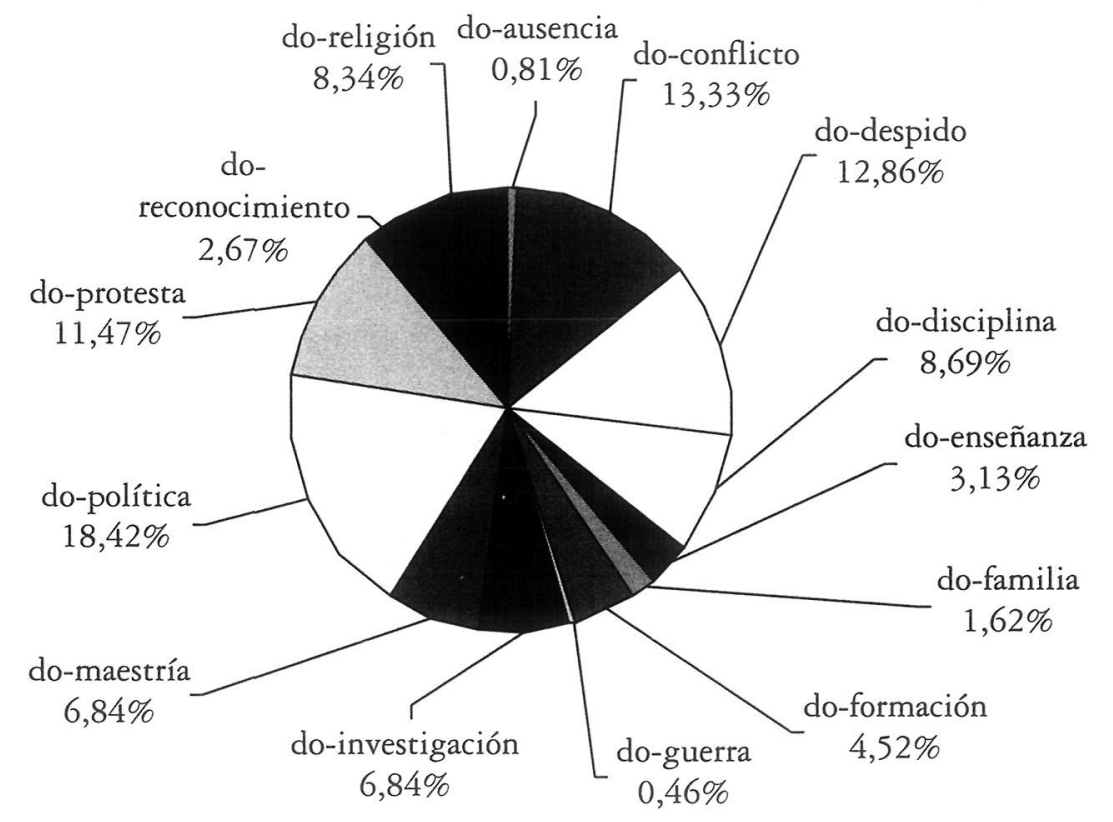

Además, resulta curioso que temas tan relevantes como la ausencia de los profesores por el creciente número de bajas que se produce, las cuestiones didácticas del proceso de enseñanza, la relación entre familia y profesores, la formación del profesorado y el reconocimiento social a labores innovadoras del profesorado, representen un porcentaje residual, menor al $2 \%$, entre el total de los textos recogidos.

En todo este trabajo de investigación mientras codificábamos la temática de cada uno de los textos sobre la figura del profesor, le atribuíamos una calificación general respecto a dicha figura. El procedimiento fue seleccionar entre imagen positiva, negativa, neutra o indeterminada ${ }^{9}$ de la figura social del profesor, teniendo en cuenta que la opción neutra se utiliza en los casos en los cuales existen referencias

9. Según la clasificación general del documento respecto al contenido que hacen J. CABERO y F. LOSCERTALES (1998) en su investigación. 
positivas y negativas simultáneamente, y la Indeterminada cuando hay referencia a la figura social pero no se expresa una valoración de la misma. Estudiando esas valoraciones sobre la imagen del profesor que se revela por periódicos, vemos que en $A B C$ y en $E l$ Mundo destacan la imagen indeterminada, con un 50,97\% y un $42,86 \%$ respectivamente, y en ambos casos el siguiente porcentaje relevante es el de la imagen negativa, con un $22,58 \%$ y un $25 \%$ en cada caso. En La Vanguardia y en Sur también destaca la imagen indeterminada, con un 50\% y un 34,71\% respectivamente, y en estos dos periódicos los siguientes porcentajes relevantes se refieren a la imagen positiva con respecto a la figura del profesor, con un $23,26 \%$ y un $28,82 \%$. El País tiene un comportamiento muy singular, con un $43,75 \%$ subraya la imagen indeterminada del profesor, en segundo lugar reparte bastante equitativamente los porcentajes entre una imagen negativa $(21,09 \%)$ y una imagen neutra $(20,31 \%)$, siendo en esta ocasión la imagen positiva la que goza de menor presencia. Así pues, concluimos que en la prensa escrita en general no se enjuicia la imagen del profesor y, en las ocasiones en las que hay que valorar, son los periódicos de menor difusión los que se inclinan más por ofrecer una imagen positiva del profesor, mientras que el resto suele ofrecer una imagen negativa, o también neutra en el caso de El País, que ofrece el ejemplo más equilibrado con respecto a una imagen negativa o positiva de estos profesionales. Son varias las investigaciones (Pérez Serrano, 1984; Nieto, 1986; Cabero y Loscertales, 1998) que ya habían destacado ese carácter de indiferencia con que se suelen tratar las cuestiones educativas.

Así concluimos (ver Tabla 2) que respecto al profesor, en la mayoría de los casos, la prensa no entra a valorar su imagen, mientras que el siguiente porcentaje expresa que respecto al profesorado hay también una cantidad de textos periodísticos que transmiten una valoración negativa. No obstante, la no-elección, en sí misma, ya es un hecho significativo de los medios de comunicación.

TABLA 2

CALIFICACIÓN DEL TEXTO RESPECTO A LA IMAGEN DEL PROFESOR

\begin{tabular}{|l|r|r|}
\hline Calificación general de la imagen del profesor & Frecuencia & Porcentaje \\
\hline Positiva & 155 & 17,96 \\
Negativa & 193 & 22,36 \\
Neutra & 138 & 15,99 \\
Indeterminada & 377 & 43,69 \\
\hline
\end{tabular}

El último análisis de frecuencias realizado es el de las palabras clave empleadas para la selección de los textos (ver Gráfico 8). En primer lugar es necesario aclarar que el número de palabras clave no coincide ni con el número de textos 
recogidos, ni con el número de temas tratados, puesto que en un texto se puede haber detectado sólo una de las palabras clave o varias de ellas, y con la temática ocurre igual.

GRÁFICO 8

PorCENTAJES DE LAS PALABRAS CLAVE LOCALIZADAS RELATIVAS A PROFESORES

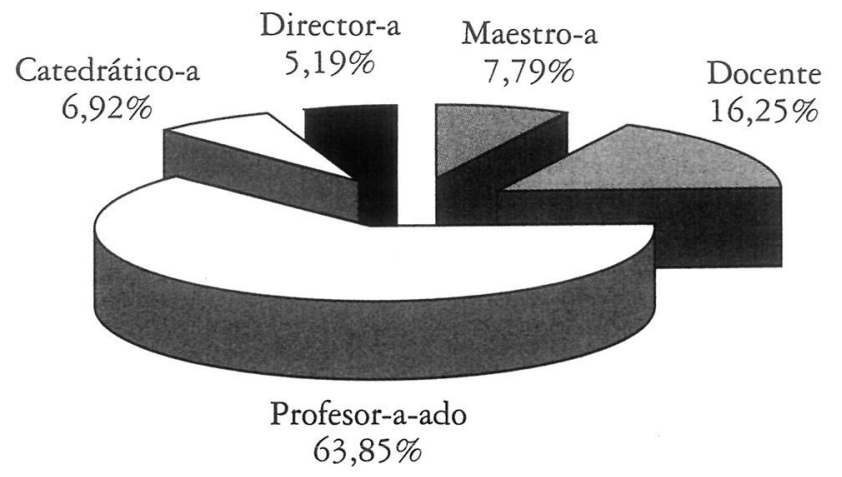

Palabras clave relativas a la figura del profesor se han encontrado 910, entre las cuales destaca la alta cantidad de "profesor-a-ado" con un $63,85 \%$ ( $f=581$ ) por lo que sobresale con bastante diferencia sobre la siguiente palabra clave.

Para estudiar si los periódicos tienen preferencias especiales en el uso de estas palabras clave, estudiemos cómo se distribuyen entre ellos. En todos los periódicos sobresale el uso de "profesor-a-ado", seguido aunque de lejos del empleo de "docente". En el caso de El Paîs, La Vanguardia y Sur, la palabra clave siguiente es "maestro-a", en el $A B C$ es "director-a", mientras que en El Mundo es "catedrático-a".

Este análisis demuestra que la mayoría de las referencias a profesores se hacen con carácter general subrayando la condición social ("profesor-a-ado" O "docente"). En el momento de inclinarse hacia un nivel educativo: El País, La Vanguardia y Sur muestran mayor interés en los niveles primarios ("maestro-a"), $A B C$ destaca los puestos de poder dentro del profesorado ("director") y El Mundo presta especial atención al nivel más alto de la enseñanza reglada ("catedrático-a"). Esto se traduce en un interés de cada grupo periodístico hacia los distintos niveles y categorías en el ámbito educativo; es decir, detrás de la elección de la palabra clave a emplear en cada documento sobre educación existe una intención implícita de la propia línea editorial de influir sobre la imagen de profesores que tenemos los lectores. 


\section{CONCLUSIONES}

El desarrollo del trabajo de campo nos ha permitido llegar a una serie de afirmaciones:

1. Hay relación directa entre mayor difusión y mayor tratamiento de cuestiones sobre profesores. En el periódico nacional de mayor difusión -El País- es donde se han encontrado mayor número de referencias al profesorado, y en segundo lugar en otro periódico de tirada nacional -El Mundo-; asimismo los periódicos se distinguen fundamentalmente por las temáticas tratadas.

2. La publicación de textos periodísticos referentes a profesores se concentra en los meses de inicio del curso académico (septiembre y octubre) y en aquellas fechas en las que se da la coincidencia de diversos acontecimientos políticos y sociales relacionados con profesores.

3. En las noticias sobre profesores se demuestra un alto interés por las cuestiones de actualidad, haciendo alusión siempre a lo más inmediato, por lo que se pierde la riqueza y profundidad que nos aportan los conocimientos sobre el pasado o sobre las consecuencias futuras. Esto sucede fundamentalmente porque la caducidad de las noticias periodísticas es muy corta; así pues, se prima la inmediatez sobre la comprensión y la reflexión. De este modo, por ejemplo, las discusiones en torno a políticas y leyes educativas del momento suelen reflejarse en la prensa con un considerable aumento de documentos referidos a profesores.

4. ${ }^{\circ}$ Los textos donde aparece la figura del profesor no suelen presentarse en las portadas de los periódicos, no se acompañan de gráficos, ni tampoco acostumbran a ocupar grandes extensiones, porque esos elementos se reservan para cuestiones que la editorial considere de mayor importancia. Sin embargo, sí suelen acompañarse de fotografías con marcado carácter interpretativo sobre el contenido del texto.

5.. Con respecto a la imagen de los profesores, se puede afirmar que la prensa tiende a resaltar sucesos muy particulares que les han ocurrido, bien sea entre ellos mismos, con familiares o con la Administración; en detrimento de referencias al proceso de enseñanza-aprendizaje. Toda la población parece entender de educación, pero a la hora de estar informados prevalece el interés por los sucesos y cuestiones políticas; es decir, prima la polémica y los escándalos, sobre el conocimiento y la profundización en cuestiones del ámbito de la enseñanza.

6. En la mayoría de los textos periodísticos sobre profesores no se entra a valorar la imagen social de este profesional, pero cuando se emiten valoraciones se suele transmitir una imagen negativa del profesorado por encima de las valoraciones positivas o neutras. Lo más común, con la figura del profesor, es que la prensa diaria escrita prefiera no expresar valoraciones.

7. Para la figura del profesor se suelen emplear terminologías generalistas, pues para los sucesos sociales interesa la función social, y no tanto en el nivel académico en que se encuentran. Sin embargo, si por cualquier razón se pretende subrayar el nivel educativo que se trata, entonces se emplean las distintas terminologías existentes, a excepción de la palabra "maestro-a" que también se suele 
emplear para expresar dominio y capacidad en algún arte u oficio distinto a la enseñanza. Se observa, no obstante, que cada grupo periodístico demuestra cierto interés por un nivel educativo en particular.

8. ․ Cada periódico distribuye las referencias a profesores de forma peculiar entre las secciones de su periódico; así, algunos optan por emplear la sección "Sociedad" de carácter general y otros usan la sección "Regional" O "Local"-según el caso- para contextualizar el documento y llamar así la atención del lector. Es decir, las noticias referidas a profesores son más sucesos o relatos de acontecimientos que análisis sobre cuestiones educativas; por eso estos textos se concentran en secciones generales de carácter social, y no en la sección específica para cuestiones relativas a educación.

9.. Al emplear mayoritariamente el género periodístico de la noticia, son reporteros los que tratan la información, y no personas especializadas en temáticas educativas cuyas valoraciones resultarían más fiables y profundas. Por otro lado, que la noticia y el reportaje sean los géneros periodísticos más empleados implica la no presencia de opinión con respecto a esta figura social, puesto que el periodista se limita a informar y a describir los acontecimientos. Así se produce la comunicación mediada, convirtiendo la realidad, o lo que entienden de ella, en noticia. Esto nos lleva a afirmar que en los temas que hacen referencia a la imagen del profesorado se informa más que se opina.

$10 .$. Se destacan las relaciones de los profesores con asuntos legislativos y políticos. Éstos son temas de bastante actualidad y dotados de cierta polémica social, de ahí que despierte el interés de los medios de comunicación de masas. Además, cuando se publica en prensa algún documento en el que se menciona al profesor, se suele hacer ofreciendo una visión conflictiva de dicha figura.

11. La prensa de carácter nacional tiende a subrayar las cuestiones polémicas que rodean al profesor, exceptuando a $E l$ País que, al igual que la prensa regional o provincial, también enfatiza las iniciativas educativas. Estos últimos periódicos de menor difusión señalan además las cuestiones que resaltan la maestría de los profesionales de la enseñanza, así como condiciones particulares de su entorno sobre disciplina, que son problemas ya conocidos suficientemente por el resto del país como para resultar novedosos en periódicos de mayor tirada. Es posible decir que los periódicos nacionales, al tener una panorámica más amplia, se alejan de la realidad concreta, y además corren el peligro de influenciarse por las corrientes políticas y por las ideologías dentro de la empresa editora.

12. ${ }^{\circ} \mathrm{El}$ tratamiento de los temas es superficial. Es evidente que las cuestiones relativas a las condiciones laborales y legislativas del profesorado son temas de actualidad en la prensa; sin embargo temas tan relevantes como la formación de los profesores se hallan ausentes en el conjunto de las temáticas reflejadas. Por consiguiente, podemos afirmar que los temas tratados son superficiales y se refieren a aspectos llamativos y de detalle, olvidando temas que darían una imagen más real, profesional y científica del profesorado. 
13. La imagen social de la enseñanza influye sobre el público; sus mensajes están cargados de significaciones que alimentan y modifican actitudes, estereotipos e incluso prejuicios. Cuando se valora la imagen del profesor ésta es de carácter negativo. No obstante, en la mayoría de los casos no se emiten juicios de valor, demostrando así una neutralidad que bien podría interpretarse como el deseo de no pronunciarse sobre temas controvertidos.

14. ${ }^{\circ}$ Predomina una imagen negativa del profesorado. En esta línea de calificaciones, hemos encontrado una visión diferente de la imagen del profesorado en función del ámbito de difusión del periódico. De esta forma sabemos que los periódicos de ámbito regional o provincial se inclinan más por reflejar una imagen positiva del profesor, mientras que los periódicos de difusión nacional reflejan una imagen más negativa, incluso en sus tiradas autonómicas.

15..$^{-}$Existen diferencias en la tendencia de cada periódico a centrarse en un nivel concreto de la enseñanza. En el caso de El País, La Vanguardia, ABC y Sur, se reflejan en más ocasiones referencias a la enseñanza primaria, con mayor proporción de alusiones a "maestros-as"; mientras que en El Mundo la tendencia señala hacia la enseñanza secundaria y universitaria, con menciones a "catedráticos-as". Quizás, lo más significativo es el elevado uso de referencias a esta figura sin subrayar las distinciones entre niveles educativos, es decir, con alusiones a "profesores-as" o "docentes", de lo cual se deduce que lo que interesa a los medios de comunicación es resaltar la condición de protagonistas del proceso enseñanzaaprendizaje.

16. ${ }^{\circ}$ El tratamiento formal, la valoración y la temática del documento varían de un periódico a otro. Se puede decir que cada grupo periodístico, en función de su línea editorial, realiza un tratamiento diferente de los textos referidos a profesores. En concreto, aunque se han admitido varias generalidades en cuestiones formales como extensión, género periodístico, presentación, periodo de publicación, ubicación en el periódico..., existen notables diferencias en las secciones empleadas, en la imagen que se transmite y en las temáticas tratadas, según el grupo periodístico concreto.

En general se puede decir que toda la población parece entender de educación, pero a la hora de estar informados prevalece el interés por los sucesos polémicos o escandalosos. Aun siendo la educación un tema muy importante para nuestra sociedad, a sus profesionales no se les presta la suficiente atención en los medios de comunicación social.

Para concluir hacemos notar también que las temáticas planteadas sobre el profesorado suelen ser las que implican situaciones conflictivas de los profesores por asuntos legislativos y/o políticos. Éstos son temas de bastante actualidad y dotados de cierta polémica social, de ahí que despierten el interés de los medios de comunicación de masas. Los temas tratados son superficiales y se refieren a aspectos llamativos y de detalle, olvidando temas que darían una imagen más real, profesional y científica del mundo de la educación. 
BiBLIOGRAFÍA

ABRAHAM, A. (1987) El mundo interior de los enseñantes. Aportes psicopedagógicos y terapéuticos para una mejor comprensión del universo intimo del enseñante, sus conflictos $y$ dificultades. Barcelona, Gedisa.

- (1993) La personalidad de los docentes, en JUIDÍAs, J. y LOSCERTALES, F. (coords.). El rol del docente: un enfoque psicosocial. Sevilla-Bogotá, Muñoz Moya y Montraveta editores, 31-45.

BARTOLOMÉ, D. y SEVILLANO, M. $\stackrel{a}{\text { L. }}$ (1989) Prensa: su didáctica, teoria, experiencias y resultados. Madrid, Mateu Cromo Artes Gráficas/UNED.

BAZARRA, L.; CASANOVA, O. y GARCÍA UGARTE, J. (2004) Ser profesor y dirigir profesores en tiempos de cambio. Madrid, Narcea.

BRANSFORD, J. D. (ed.) (2001) How people learn brain: brain, mind, experience and school. Washington, National Academy Press.

BREUSE, E. (1984) Identificación de las fuentes de tensión en el trabajo profesional del enseñante, en ESTEVE, J. M. (ed.). Profesores en conflicto. Repercusiones de la práctica profesional sobre la personalidad de los enseñantes. Madrid, Narcea, 143-161.

BUXARRAIS, M. ․ R. (1997) La formación del profesorado en educación en valores. Propuestas $y$ materiales. Bilbao, Desclée De Brouwer.

CABERO, J. y LOSCERTALES, F. (eds.) (1998) ¿Cómo nos ven los demás? La imagen del profesor $y$ la enseñanza en los medios de comunicación social. Sevilla, Servicio de Publicaciones de la Universidad de Sevilla.

COOPER, C. L. y TRÁVERS, C. J. (1997) El estrés de los profesores. La presión en la actividad docente. Barcelona, Paidós.

COX, S. y HEAMES, R. (2000) Cómo enfrentar el malestar docente. Estrategias e ideas prácticas para los tutores y sus alumnos. Barcelona, Octaedro.

ESTEVE, J. M. (1987) El malestar docente. Barcelona, Laia.

- (1997) La formación inicial del profesorado de secundaria. Barcelona, Ariel.

- (2003) La tercera revolución educativa. La educación en la sociedad del conocimiento. Barcelona, Paidós.

ESTEVE, J. M. y FRACCHIA, F. B. A. (1984) L'image des enseignants dans les moyennes de communication de masse, European Journal of Teacher Education, 7 (2), 203-209.

ESTEVE, J. M.; FRANCO, S. y VERA, J. (1995) Los profesores ante el cambio social. Barcelona, Anthropos.

FAURE, E. (1974) Aprender a ser. Madrid, Alianza-Unesco.

FERNÁNDEZ ENGUITA, M. (1990) La escuela a examen. Un análisis sociológico para educadores y otras personas interesadas. Madrid, Eudema.

Fernández SÁnCheZ, M. a M.; NAVARro, C.; Higuera, C. y Martínez CaStro, E. (1993) Encuesta al profesorado de primaria y secundaria de la enseñanza pública: opiniones $y$ actitudes ante sus condiciones de trabajo. Madrid, MEC.

FURLONG, V. J.; HIRST, P. H.; Miles, S. y POCKLINGTON, K. (1988) Initial teacher training and the role of the school. Philadelphia, Open University Press.

GARCía GARCÍA, E. (1986) Función, estatus y rol del profesor, en MAYOR, J. (dir.). Sociología y psicología social de la educación. Madrid, Anaya, 381-421.

GARCÍA HERRERO, G. A. (2001) Imagen y comunicación en temas sociales. Zaragoza, Libros Certeza.

GIL Villa, F. (1996) Sociología del profesorado. Barcelona, Ariel. 
GIMENO, J. (1993) Conciencia y acción sobre la práctica como liberación profesional de los profesores, en IMBERNON, F. (coord.). La formación permanente del profesorado en los países de la CEE. Barcelona, ICE/Horsori, 53-92.

GOBLE, N. M. (1980) El profesor en un mundo de cambio, en GOBLE, N. M. y PORTER, J. F. La cambiante funciôn del profesor. Madrid, Narcea, 13-101.

GONZÁlEZ GARCÍA, J. A. (1986) Escuela y sociedad. Sociología del sistema escolar, en MAYOR, J. (dir.). Op. cit., 470-491.

GROS, B. (2004) Ser profesor: palabras sobre la docencia universitaria. Barcelona, Octaedro.

HARgreaVes, A. (1996) Profesorado, cultura y postmodernidad. Cambian los tiempos, cambia el profesorado. Madrid, Morata.

HIGUERAS, I. (2001) Valor comercial de la imagen: aportaciones del "right of publicity". Pamplona, Eunsa.

HOYLE, E. (1969) The role of the teacher. London, Routledge \& Kegan Paul.

IMBERNON, F. (coord.) (1994) La formación y el desarrollo profesional del profesorado. Hacia una nueva cultura profesional. Barcelona, Graó.

KeEne, M. (1995) Práctica de la fotografía de prensa. Una guia para profesionales. Barcelona, Paidós.

LOSADA DíAZ, J. C. (2002) Prensa e imagen corporativa en la universidad: los püblicos internos. Murcia, Universidad Católica de San Antonio.

LOSCERTALES, F.; MARÍN, M. y NÚÑEZ, T. (2000) Imagen social del profesorado: Un estudio a partir de los Medios de Comunicación, Prensa y TV, Revista Interuniversitaria de Formación del Profesorado, 39, 147-156.

MARCELO, C. (1994) Formación del profesorado para el cambio educativo. Barcelona, PPU.

MERAZZI, C. (1983) Apprendre a vivre les conflicts: une tache de la formation des enseignants, European Journal of Teacher Education, 6 (2), 101-106.

Miguel DíAZ, M. de (dir.) (1996) El desarrollo profesional docente y las resistencias a la innovación educativa. Oviedo, Servicio de Publicaciones de la Universidad de Oviedo.

MOLlo, S. (1980) La condición social de los enseñantes, en DeBesSe, M. y MiAl_ARET, G. La función docente. Barcelona, Oikos-Tau, 55-82.

MORIN, E. (2001) Los siete saberes necesarios para la educación del futuro. Barcelona, Piados Ibérica.

Nieto, S. (1986) La temática educativa en la prensa. Análisis de contenido. Valladolid, Server-Cuesta.

ORTIZ ORIA, V. M. (1995) Los riesgos de enseñar: La ansiedad de los profesores. Salamanca, Amarú Ediciones.

PABLOS, J. C. de (1997) El papel del profesor en una sociedad de cambio. Granada, Editorial Universidad de Granada.

PÉrez Gómez, A. I. (1988) El pensamiento práctico del profesor: implicaciones en la formación del profesorado, en VILLA, A. (coord.). Perspectivas y problemas de la función docente. Narcea, Madrid, 128-148.

PÉRez SERRANO, G. (1984) El análisis de contenido de la prensa. Madrid, UNED.

PIÑUEL, J. L. (2004) La imagen de la educación en la prensa española. Madrid, Centro Nacional de Información y Comunicación Educativa.

REGAN, H. B. (2002) El profesor: una nueva definición y un nuevo modelo de evaluación y actualización profesional. Madrid, Editorial Centro de Estudios Ramón Areces.

Rodríguez Penin, A. (2002) Entrevista: Ana Rodríguez Penin, Andalucía Educativa, 31, 37-39. 
SALA, T. (2002) Crónica de un profesor en secundaria: el mundo de la enseñanza desde dentro. Barcelona, Península.

SHULMAN, L. S. (1987) Knowledge and teaching: foundations of the new reform, Harvard educational Review, 57 (1), 1-22.

TOFFLER, A. (1972) El sbock del futuro. Barcelona, Plaza y Janés.

VERA, J. (1988) La crisis de la función docente. Valencia, Promolibro.

ViLCHES, L. (1987) Teoría de la imagen periodística. Barcelona, Paidós.

VOLI, F. (1996) La autoestima del profesor. Manual de reflexión y acción educativa. Madrid, PPC.

WANJIRU, C. (1995) La ética de la profesión docente. Pamplona, Eunsa. 